\title{
DOPPLER CAROTID ARTERY STUDIES IN ASYMMETRIC GLAUCOMA
}

\author{
C. O’BRIEN*, V. SAXTON†, R. P. CRICK*, H. MEIRE* \\ London
}

\begin{abstract}
SUMMARY
Doppler carotid artery studies were performed in 12 glaucoma patients with marked asymmetry in bilateral visual field loss. The resistance index and the pulsatility index of the internal carotid artery velocity waveforms were significantly greater on the same side as the eye with the greater visual field loss. The increased resistance to blood flow in the internal carotid artery on the side with advanced field loss might predispose the eye on this side to the effects of raised intraocular pressure by causing a reduction in the perfusion pressure at the optic nerve head. The role of ocular perfusion pressure in the pathogenesis of glaucoma is discussed. More extensive studies are necessary.
\end{abstract}

The relative importance of raised intraocular pressure to vascular insufficiency in causing optic nerve damage and consequent visual field loss in primary chronic open angle glaucoma has long been debated. ${ }^{1}$ It is likely that both factors, as well as weakness of the supporting glial and connective tissue of the optic nerve head, as shown by Quigley, ${ }^{2,3}$ are interactive and in any particular case they contribute to a varying extent. The evidence that carotid artery disease plays a role in the causation of glaucomatous visual field loss is anecdotal, based largely on isolated case reports ${ }^{4,5}$ although supported by the ophthalmodynamometry studies of Drance. ${ }^{6,7}$ The present study set out to determine whether patients with a marked asymmetry in the severity of visual field loss had evidence of significantly worse carotid artery disease on the same side as the eye with advanced field loss.

\section{SUBJECTS AND METHODS}

Patients with primary open angle glaucoma showing advanced visual field loss in one eye and early field loss in the fellow eye were studied. The fields of vision were examined using the Friedmann Visual Field Analyser and

From: *Department of Ophthalmology, $†$ Department of Radiology at King's College Hospital, London.

Correspondence to: Mr. C O'Brien FCOphth, St Paul's Eye Hospital, Old Hall Street, Liverpool L3 9PF. recorded using a numerical scoring system. ${ }^{8}$ We arbitrarily defined a score of 15 or less as representing advanced field loss and a score of 40 or more to represent early field loss. Nineteen patients who had this marked degree of unequal field loss were identified from the computerised data base of patients attending the glaucoma clinic. Three of these 19 patients were found to have other ocular or neurological disease which might cause loss of visual field, and were therefore excluded from the study. The remaining 16 patients were contacted by letter and invited to participate in the study; two were unable to attend because they had moved out of the region and three declined the invitation.

Three patients were known to have systemic hypertension and three were diabetic. Four patients had diastolic blood pressures of $100 \mathrm{mmHg}$ recorded on the day of the carotid Doppler investigations. All 12 patients were on glaucoma medications and three had previous filtration surgery. Four patients had started pressure lowering therapy at a different hospital and we do not have the presenting intraocular pressure at the time of diagnosis in these four patients. Seven of the eight patients presenting to this department at the time of diagnosis had higher ocular pressures in the eye with advanced field loss than in the fellow eye with early field loss.

Common carotid and internal carotid artery scans were performed on the remaining 12 patients using a Diasonics CV400 ultrasound machine with a $7.5 \mathrm{MHz}$ transducer using a range gated pulsed Doppler with a frequency of 3.0 MHz. The patients were recumbent in position with the head turned slightly away from the side under investigation (Fig. 1). Measurements of the pulsatility index, resistance index, and the volume blood flow $(\mathrm{ml} / \mathrm{min})$ were calculated from the images obtained. ${ }^{9-11}$ The pulsatility index (PI) and the resistance index (RI) are both influenced by the resistance to blood flow, i.e. they increase proximal to a region of increased resistance or stenosis. They are calculated from the graphical representation of the systolic and diastolic arterial blood velocities during the cardiac cycle (Fig. 2). In order to measure vol- 


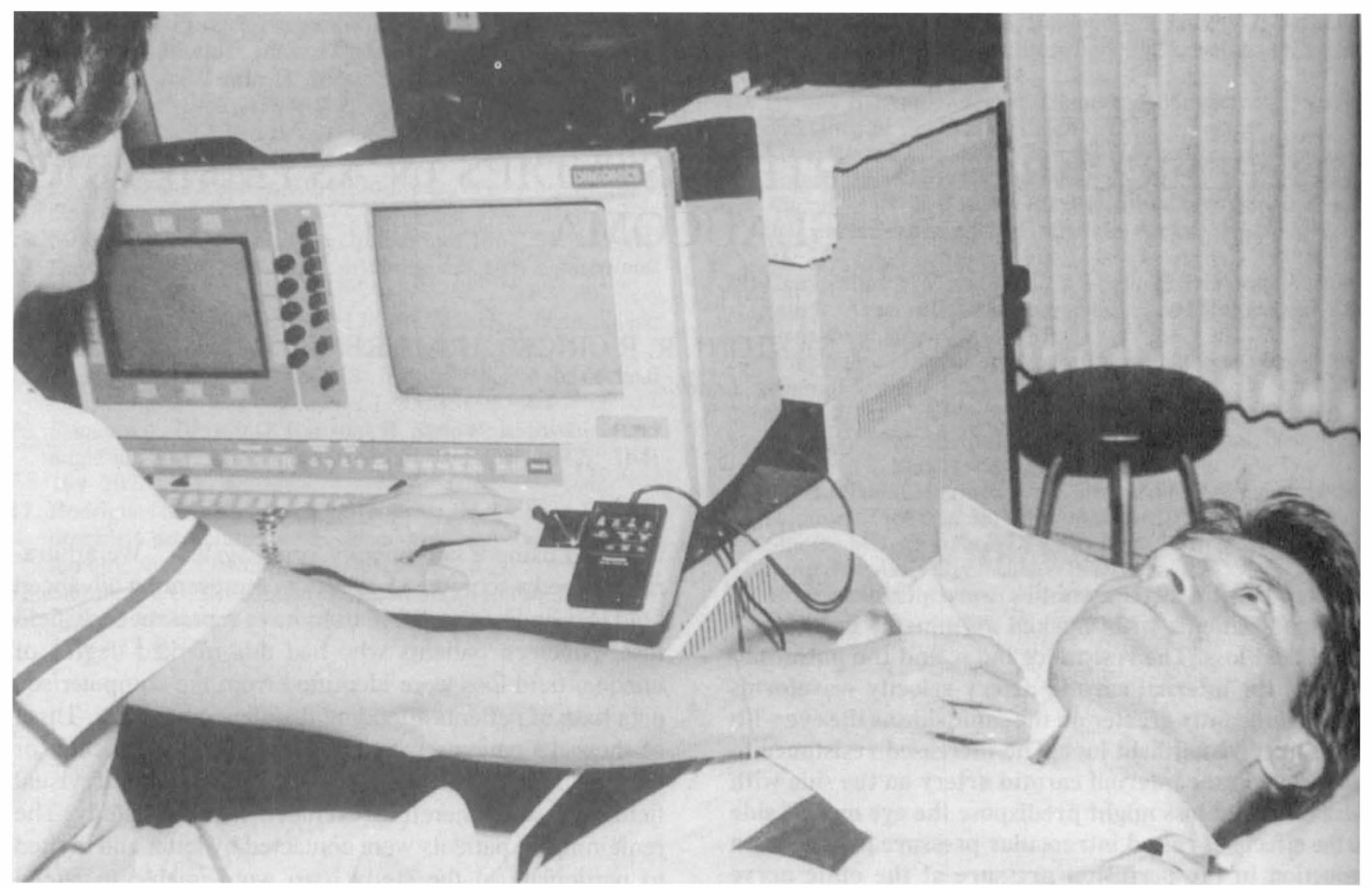

Fig. 1. Position of the patient and ultrasound transducer for examination of the right carotid artery.

ume blood flow, the time averaged velocity was measured over four cardiac cycles using the equipment's integral software. The vessel diameter was measured from the image, and the equipment calculated the volume blood flow in $\mathrm{ml} / \mathrm{min}$. The measurement of volume blood flow is reported to be less reliable than RI and PI in the detection of pathological conditions, owing to inaccuracies and errors in the calculation of both flow velocity and vessel cross-sectional area. ${ }^{10}$ Of the twelve patients, two had common carotid artery measurements only, because it was impossible to get adequate visualisation of the internal carotid artery to obtain reliable measurements. The operator was masked as to the status of the visual field.

\section{RESULTS}

The mean and standard deviations of the carotid artery measurements are presented in the Table. Statistically significant differences (Student's paired t-test) were seen between the side with advanced visual field loss and the side with early field loss in the pulsatility index and the resistance index of the internal carotid artery, but not in the common carotid results. The greater values of PI and RI for the internal carotid blood flow occurred on the side with advanced field loss. Volume blood flow comparisons were not statistically significant for either the internal or common carotid arteries.

\section{DISCUSSION}

Previous reports of carotid Doppler ultrasonography in glaucoma patients have shown an increased tendency to stenotic lesions and a reduced flow in the carotid arteries on the side with the greater glaucomatous damage. ${ }^{12,13}$ The findings of the present study indicate a significantly greater resistance to blood flow in the internal carotid artery on the side with advanced visual field loss. This might predispose the ipsilateral eye to the effects of raised intraocular pressure by reducing the perfusion pressure at the otpic nerve head.

The main determinants of ocular perfusion pressure are the systemic arterial blood pressure (ABP) and intraocular pressure (IOP). Armaly has shown that the rate of blood flow in the optic nerve head region depends on the relationship between $\mathrm{ABP}$ and $\mathrm{IOP},{ }^{14}$ Hayreh later demonstrated that the circulation in the choroid, peripapillary choroid and prelaminar region of the optic nerve is dependent on the balance between ABP and IOP. ${ }^{15}$

A reduction in the action potential of the optic nerve has been shown in an animal model by increasing the IOP and lowering the mean $\mathrm{ABP}{ }^{16}$. Furthermore, a raised mean $\mathrm{ABP}$ was found to be protective against the effects of a high IOP. Grehn has demonstrated that the action potential in the retinal ganglion cell axon during periods of shortterm IOP elevation is dependent on the perfusion pressure and not on the absolute height of the IOP. ${ }^{17}$ The amplitude of the pattern reversal electroretinogram in ocular hypertensives has been shown to be positively correlated with the diastolic blood pressure. ${ }^{18}$ In the present study, three patients were on systemic antihypertensive treatment; four 


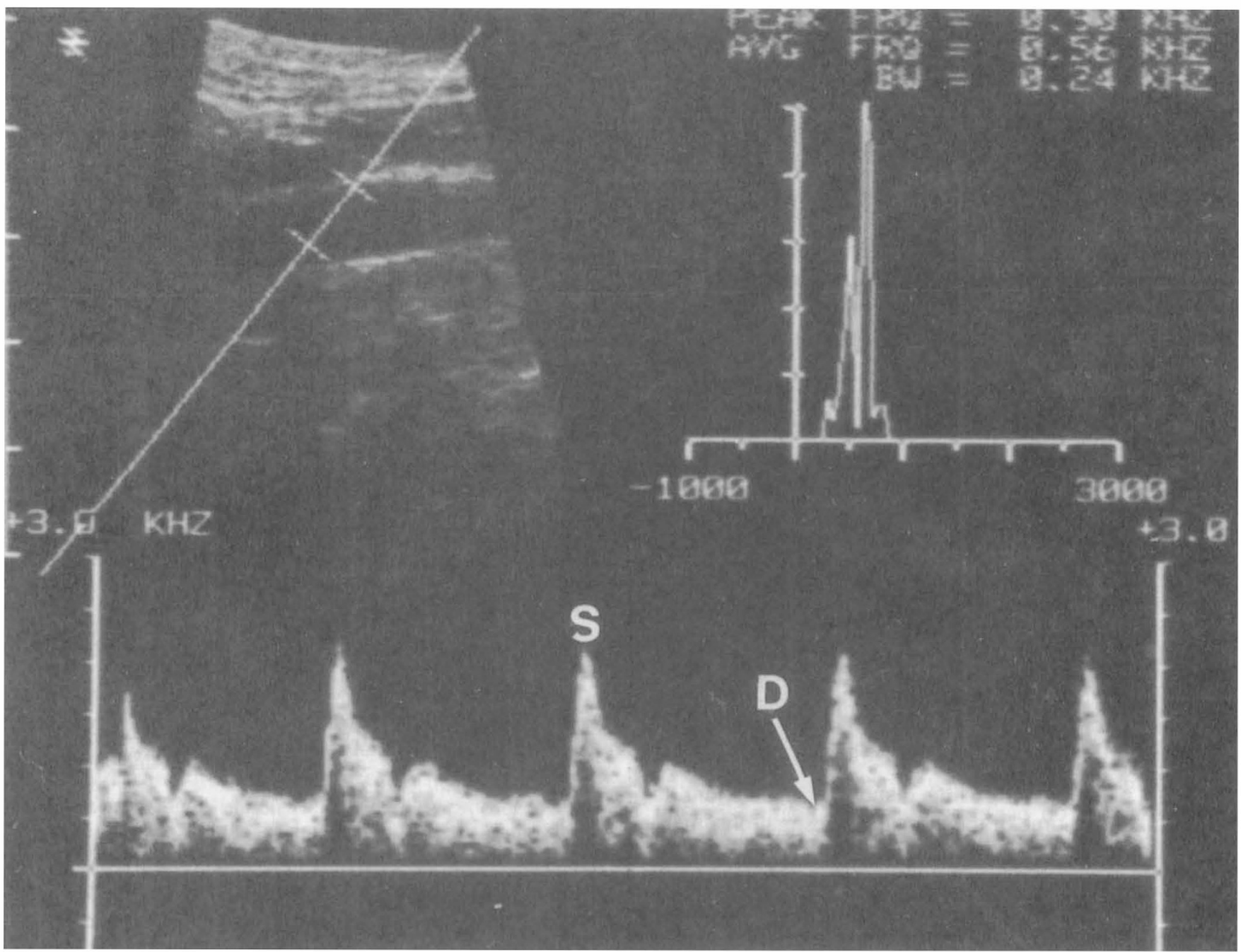

Fig. 2. Duplex (image and Doppler) scan of the common carotid artery. The peak systolic velocity (S) and end diastolic velocity (D) are indicated.

The resistance index $(R I)$ is defined as $\frac{S-D}{S}$ and the pulsatility index $(P I)$ as $\frac{S-D}{\text { mean velocity }}$

patients had a diastolic ABP of $100 \mathrm{mmHg}$ at the time of the Doppler carotid studies.

Drance found that patients with uniocular open angle glaucoma had diastolic perfusion pressures (defined as "orbital diastolic pressure as obtained by ophthalmodynamography minus intraocular pressure") that were considerably lower in the affected eye than an age matched normal population sample. ${ }^{6}$ His group also stated that "the combination of a low systemic blood pressure plus a relative obstruction in the large vessel circulation (carotid or vertebrobasilar arteries ) may lead to a reduced supply of blood to the eyes, and therefore a greater susceptibility to damage". 7 It has recently been shown by McFadzean et al., that this combination, i.e. carotid artery stenosis and systemic hypotension, significantly reduced optic nerve blood flow in experiments on primates. ${ }^{19}$

Table I. Doppler carotid artery measurements (Mean \pm S.D.)

\begin{tabular}{|c|c|c|c|}
\hline & $\begin{array}{l}\text { Early Visual } \\
\text { Field Loss }\end{array}$ & $\begin{array}{l}\text { Advanced Visual } \\
\text { Field Loss }\end{array}$ & $\mathrm{p}$ Value \\
\hline \multicolumn{4}{|l|}{ Common Carotid Artery $(\mathrm{n}=12)$} \\
\hline Pulsatility Index & $1.74 \pm 0.35$ & $1.55 \pm 0.34$ & NS \\
\hline Resistance Index & $0.74 \pm 0.05$ & $0.73 \pm 0.05$ & NS \\
\hline Volume Blood Flow (ml/min) & $460 \quad 191$ & $438 \quad 200$ & NS \\
\hline \multicolumn{4}{|l|}{ Internal Carotid Artery $(n=10)$} \\
\hline Resistance Index & $0.65 \pm 0.05$ & $0.71 \pm 0.07$ & 0.032 \\
\hline Volume Blood Flow (ml/min) & 21294 & $261 \quad 114$ & NS \\
\hline
\end{tabular}

NS $=$ not significant 
A low mean diastolic blood pressure has been identified as a major risk factor in progressive field loss in glaucoma. ${ }^{20}$ A low systemic blood pressure to intraocular pressure ratio was significantly associated with the presence of visual field defects in a large scale epidemiology study. ${ }^{21}$ Glaucoma patients with progressive field loss were found to have a low blood pressure to intraocular pressure ratio compared to those with stable visual fields. ${ }^{22}$ In a study of 12 patients with marked asymmetry in visual field loss, Drance noted that the ratio of ophthalmic artery diastolic blood pressure to the level of intraocular pressure required to induce a scotoma was markedly lower on the side with advanced glaucoma. ${ }^{23}$

However, not all the evidence supports this viewpoint. Jampol and Miller reported that five ocular hypertensive patients with severe bilateral carotid artery disease followed over a duration of between three to 12 years did not develop glaucomatous disc or visual field changes. ${ }^{24}$ This finding would appear to cast doubt on the hypothesis that in the presence of raised IOP, carotid artery disease predisposes to glaucomatous damage. A careful review of the patients in that study shows that three of the five patients had systemic hypertension and another patient had a blood pressure of $180 / 80 \mathrm{mmHg}$; it is quite possible that the elevated systemic $\mathrm{ABP}$ in these patients might have protected these eyes against the effect of raised IOP by maintaining an adequate perfusion pressure.

All 12 patients were using glaucoma medications to lower IOP at the time of the Doppler investigations, making it difficult to comment on the role of IOP in the causation of the visual field loss. Seven of the eight patients in whom the IOP at presentation was known had an asymmetry in IOP which matched the asymmetry in field lossthe eye with the higher IOP having advanced field loss. The role of IOP in asymmetric disease is unclear. It has been reported that $50 \%$ of primary open angle glaucoma patients with monocular field loss had no identifiable cause for the asymmetry. ${ }^{25}$ Two recent investigations of low tension glaucoma found an asymmetry in intraocular pressure associated with an asymmetry in disc damage and visual field loss in some but not all patients. ${ }^{26,27}$

In our study of Doppler carotid ultrasound in glaucoma patients with marked asymmetry in visual field loss, there were significantly larger resistance and pulsatility indices, indicating an increased resistance to blood flow, in the internal carotid artery on the side with the greater visual field loss. The number of patients in this study is small, due in part to our decision to include only those patients with a marked asymmetry in field loss. The results suggest that a larger study is now warranted, which should also include patients with a lesser degree of asymmetry.

\section{REFERENCES}

1. Minkler DS and Spaeth GL: Optic nerve damage in glaucoma. Surv Ophthalmol 1981, 26: 128-48.

2. Quigley HA and Green WR: The histology of human glaucoma cupping and optic nerve damage: clinicopathologic correlation in 21 eyes. Ophthalmology 1979, 86: 1803-27.

3. Quigley HA, Dunkelberger GR, Green WR: Chronic human glaucoma causing selectively greater loss of large optic nerve fibres. Ophthalmology 1988, 95: 357-63.
4. Harrington DO: The pathogenesis of the glaucoma field. Am J Ophthalmol 1959, 47: 177-85.

5. François $J$ and Neetens $A$ : The deterioration of the visual field in glaucoma and the blood pressure. Doc Ophthalmol 1970, 28: 70-132.

6. Drance SM, Wheeler C, Pattullo M: Uniocular open-angle glaucoma. Am J Ophthalmol 1968, 65: 891-902.

7. Feldman F, Sweeney VP, Drance SM: Cerebro-vascular studies in chronic simple glaucoma. Can J Ophthalmol 1969, 4: 358-64.

8. Crick RP: Prevention of blindness from glaucoma using the King's College Hospital computerised problem orientated medical record. Br J Ophthalmol 1975, 59: 236-48.

9. Gosling RG and King DH: Ultrasonic angiology. In: Harcus AW, Adamson L, eds. Arteries and Veins. Edinburgh: Churchill Livingstone, 1975: 61-84.

10. Meire HB: Vascular ultrasound. In: Grainger RG, Allison DJ, eds. Diagnostic Radiology. Churchill Livingstone, Edinburgh 1986: 2116-2119.

11. Thompson RS, Trudinger BJ, Cook CM: Doppler ultrasound waveform indices: $\mathrm{A} / \mathrm{B}$ ratio, pulsatility index and Pourcelat ratio. Br J Obs Gynae 1988, 95: 581-8.

12. Marmion VJ and Yurdukul S: An evaluation of carotid perfusion in open-angle glaucoma. In: Krieglstein GK, Leydhecker W, eds. Medikamentose Glaukomtherapie. Munchen: JF Bergmann Verlag, 1982, 111-114.

13. Marmion VJ and Aldoori M: Carotid perfusion and field loss. In: Greve EL, Heijl A, eds. Fifth International Visual Field Symposium. The Hague: Dr. W. Junk Publishers 1983, 257-260.

14. Armaly MF and Araki M: Optic nerve circulation and ocular pressure. Invest Ophthalmol 1973, 14: 724-31.

15. Hayreh SS, Revie IHS, Edwards J: Vasogenic origin of visual field defects and optic nerve changes in glaucoma. $\mathrm{Br}$ J Ophthalmol 1970, 54: 461-72.

16. Neetens A, Delaunois AL, Hendrata Y, Van Rompaey J, Van Rompu E: Effects of raised intraocular pressure and systemic blood pressure on optic pathway potential. Glaucoma 1982, ??: 259-64.

17. Grehn F and Prost M: Function of retinal nerve fibres depends on perfusion pressure: neurophysiologic investigations during acute intraocular pressure elevation. Invest Ophthalmol Vis Sci 1983, 24: 347-53.

18. Trick GL, Bickler-Bluth M, Cooper DG, Kolker AE, Nesher R: Pattern reversal electroretinogram (PRERG) abnormalities in ocular hypertension: correlation with glaucoma risk factors. Curr Eye Res 1988, 7: 201-8.

19. McFadzean RM, Graham DI, Lee WR, Mendelow AD: Ocular blood flow in unilateral carotid stenosis and hypotension. Invest Ophthalmol Vis Sci 1989, 30: 487-90.

20. Richler M, Werner EB, Thomas D: Risk factors for progression of visual field defects in medically treated patients with glaucoma. Can J Ophthalmol 1982, 17: 245-8.

21. Leske MC and Podgor MJ: Intraocular pressure, cardiovascular risk variables, and visual field defects. Am J Epidemiol 1983, 118: 280-7.

22. Reese AB and McGavic JS: Relation of field contraction to blood pressure in chronic primary glaucoma. Arch Ophthalmol 1942, 27: 845-50.

23. Drance SM: Studies in the susceptibility of the eye to raised intraocular pressure. Arch Ophthalmol 1962, 68: 478-85.

24. Jampol LM and Miller NR: Carotid artery disease and glaucoma. Br J Ophthalmol 1978, 62: 324-6.

25. Harbin TS, Podos SM, Kolker AE, Becker B: Visual field progression in open-angle glaucoma patients presenting with monocular field loss. Trans Am Acad Ophthalmol Otolaryng 1973, 81: 253-7.

26. Cartwright MJ and Anderson D: Correlation of asymmetric damage with asymmetric intraocular pressure in normal tension glaucoma (low tension glaucoma). Arch Ophthalmol 1988, 106: 898-900.

27. Crichton A, Drance SM, Douglas GR, Schulzer M: Unequal intraocular pressure and its relation to asymmetric visual field defects in low tension glaucoma. Ophthalmol 1989, 96: 1312-14. 